\title{
Partnership for Compiling Official Statistics About Higher Corporation for Specialized Economic Zones (ZonesCorp) in the Emirate of Abu Dhabi
}

\author{
Sami Nizar Daif Alla Khasawneh* Qais Saleh Al Junaibi \\ Statistical Centre of Abu Dhabi, Abu Dhabi, UAE
}

\begin{abstract}
To reduce the dependence on oil resources and implement economic reform, the Government of Abu Dhabi implemented a wide range of plans, including initiatives to encourage and facilitate foreign investment into the Emirate of Abu Dhabi. Many initiatives were implemented to accomplish these objectives, including establishing Free Zones (FZ), which offers businesses some flexibility regarding ownership rights while they are exempt from taxes on inputs and outputs of their production activities. The success of FZ in attracting businesses to implement new technologies and create job opportunities in the local economy is an important element in efforts to create new industrial infrastructure and employment opportunities in the Emirate .Measuring the success of FZ in attracting foreign investments that contribute to the economic diversification efforts, requires accurate statistical information about all business operations in these areas. To support government decision makers in their effort to measure the contribution and success of FZ in the economy, Statistics Centre Abu Dhabi (SCAD) started conducting surveys of all businesses in the Emirate's FZ. The Higher Corporation for Specialized Economic Zones (ZonesCorp) requested SCAD to conduct a comprehensive statistical survey of its foreign investment establishments. The survey project was initiated and completed within 18 months while financial and logistical data were collected from all economic establishments under their management. This paper will discuss aspects of cooperation between ZonesCorp and SCAD while producing new statistical outputs.
\end{abstract}

Keywords: Statistical Centre of Abu Dhabi (SCAD); Free Zones (FZ); Higher Corporation for Specialized Economic Zones (ZonesCorp); New Statistical Outputs; Logistical Data

DOI: $10.7176 / \mathrm{JESD} / 10-18-10$

Publication date:September $30^{\text {th }} 2019$

\section{Introduction}

Under Law No. 7 of 2008, Statistics Centre Abu Dhabi (SCAD) is the only government agency in the Emirate of Abu Dhabi responsible to; conduct surveys and collect data on Annual Economic Surveys (AES), Foreign Direct Investment (FDI), Foreign Trade (FT), any other survey, the extraction of Gross Domestic Product (GDP) and all other official statistics for Abu Dhabi Emirate.

The statistics produced by SCAD is an indispensable element in the information system of the Emirate of Abu Dhabi. It provides Government, businesses, researchers and the public with statistical information about the economy, demography, social and environmental development. Government decision makers need access to high quality official statistics to identify critical areas for development and to measure the success of previously implemented policies.

High quality official statistics, which creates trust in the government decision-making process, requires cooperation between all stakeholders in the statistical process to ensure the efficient and effective allocation of resources. Cooperation between SCAD as the producer of official statistics for the emirate and other government entities as the users of official statistics depends largely on following the internationally recognized Generic Statistical Business Process Model (GSBPM), which describes and defines the business processes for producing official statistics.

ZonesCorp is a dynamic industrial development organization located in the heart of Abu Dhabi. Launched in 2004 by the Abu Dhabi Government, they are the largest operator of purpose-built Economic zones in the United Arab Emirates.

ZonesCorp are organized into vertically integrated clusters in complementary industries that bring upstream and downstream companies together enhancing efficiencies, creating value chain benefits and provide a platform that encourages the incubation of industrial innovation.

Within just ten years, ZonesCorp has helped shape Abu Dhabi's industrial landscape through the development of world-class, fully integrated economic zones that generate almost half of the manufacturing GDP of the Emirate and play a significant role in Abu Dhabi's successful attraction of foreign direct investments. They have invested over US\$ 1 billion in infrastructure and over US\$ 3 billion in Workers' Residential Cities.

They have experienced continuous growth since opining this infrastructure to investors and currently house over 600 manufacturing facilities that are home to some of the world's leading industrial players in a variety of sectors. These manufacturers have invested more than $\$ 8$ Billion in industrial projects within the Emirate. 
During 2017, SCAD was approached by the Higher Corporation for Specialized Economic Zones to establish a joint statistical project to collect data from all establishments operating in their industrial zone. The main objective of the project was to produce new statistics, which would measure the contribution of establishments operating in the area to the economy of Abu Dhabi Emirate. These statistics would provide evidence of the success of one of the main pillars of the Abu Dhabi government's long term development initiatives, namely to attract Foreign Direct Investment (FDI) into the emirate. FDI is recognized as an important element in diversifying the domestic economy by establishing a robust industrial infrastructure based on new technologies and industrial innovation.

During the 18 months duration of the project, SCAD provided technical expertise by designing the collection instrument, collecting the data, data integration and statistical analyses, while Zonescorp contributed by providing financial and logistic support. The project concluded in November 2018 when the data collected by SCAD in cooperation with Zonescorp were used to produce new official statistics. These statistics provided evidence of the success of government policies to establish specialized zones to attract foreign investment and diversify the economy of Abu Dhabi.

\section{Methodology:}

SCAD in all its projects is applying the Generic Statistical Business Process Model (GSBPM). The GSBPM describes and defines the set of business processes needed to produce official statistics. It provides a standard framework and harmonised terminology to help statistical organisations to modernise their statistical production processes, as well as to share methods and components. The GSBPM can also be used for integrating data and metadata standards, as a template for process documentation, for harmonizing statistical computing infrastructures, and to provide a framework for process quality assessment and improvement.

The GSBPM should be applied and interpreted flexibly. It is not a rigid framework in which all steps must be followed in a strict order; instead, it identifies the possible steps in the statistical business process, and the interdependencies between them. Although the presentation of the GSBPM follows the logical sequence of steps in most statistical business processes, the elements of the model may occur in different orders in different circumstances. In addition, some sub processes will be revisited a number of times forming iterative loops, particularly within the Process and Analyse phases. The GSBPM should therefore be seen more as a matrix, through which there are many possible paths. In this way, the GSBPM aims to be sufficiently generic to be widely applicable, and to encourage a standard view of the statistical business process, without becoming either too restrictive or too abstract and theoretical.

In this paper, we will outline the steps of preparing for the specialized survey project as follows:

2.1 Specify Needs: in this phase, we met the team of ZonesCorp many times to understand their statistical needs, establish the high level objectives of the statistical outputs, identify the relevant concepts and variables for which data are required, check the extent to which current data sources can meet their needs and discussed with them the detailed requirements of the statistics. SCAD identified the statistical outputs that are required to meet their needs, clarified the required concepts to be measured by the business process from their point of view, check whether current data source could meet their requirements, and the conditions under which they would be available, including any restrictions on their use. SCAD documented the findings of the sub-processes in this phase in the form of a business case before getting approval to produce the statistics.

Figure (1): Specify Needs Phase

\begin{tabular}{|c|c|c|c|c|c|}
\hline \multicolumn{5}{|c|}{ Specify Needs } \\
\hline Identify Needs & $\begin{array}{c}\text { Consult \& } \\
\text { confirm needs }\end{array}$ & $\begin{array}{c}\text { Establish } \\
\text { output } \\
\text { objectives }\end{array}$ & $\begin{array}{c}\text { Identify } \\
\text { concepts }\end{array}$ & $\begin{array}{c}\text { Check data } \\
\text { availability }\end{array}$ & $\begin{array}{c}\text { Prepare } \\
\text { business case }\end{array}$ \\
\hline
\end{tabular}

2.2 Design Phase: during this stage, the objectives were to describe the development and design activities, and any associated practical research work needed to define the statistical outputs, concepts, methodologies, collection instruments and operational processes. Discussion between SCAD and ZonesCorp during this phase focused on the design of the statistical outputs, products and services to be produced, including the related development work and preparation of the systems and tools. The Annual Economic Survey questionnaire which is the main survey used by SCAD to collect data about the characteristics and operations of establishments in the Emaciate was used as the basis to define statistical variables to be collected via the collection instrument. SCAD and ZonesCorp decided to apply the AES for data collection from all the establishments in ZonesCorp. Design of the statistical processing methodology to be applied during the "Process" and "Analyse" phases of the project and the workflow from data collection to dissemination were consistent with the AES process. 
Figure (2): Design Phase

\begin{tabular}{|l|c|c|c|c|c|}
\hline \multirow{2}{*}{ Design outputs } & $\begin{array}{c}\text { Design } \\
\text { variable } \\
\text { descriptions }\end{array}$ & $\begin{array}{c}\text { Design } \\
\text { collection }\end{array}$ & $\begin{array}{c}\text { Design frame } \\
\text { \& sample }\end{array}$ & $\begin{array}{c}\text { Design } \\
\text { processing \& } \\
\text { analysis }\end{array}$ & $\begin{array}{c}\text { Design } \\
\text { production } \\
\text { systems \& } \\
\text { workflow }\end{array}$ \\
\hline
\end{tabular}

2.3 Build Phase: SCAD and ZonseCorp finalized the special AES questionnaire and tested the production solution to the point where it was ready for use in the "live" environment. SCAD then build the collection instruments that were used during the "Collect" phase, based on these design specifications and added new and enhanced components and services needed for the "Process" and "Analyse" phases. In addition, SCAD build new and enhanced components and services needed for the dissemination of the statistical products, including indicators, such as contribution to GDP, Research and Development and some information about logistics indicators. The systems and transformations used in the statistical business processes from data collection through to dissemination of the survey results were competed during this phase.

Figure (3): Build Phase

\begin{tabular}{|c|c|c|c|c|c|c|}
\hline $\begin{array}{c}\text { Build } \\
\text { collection } \\
\text { instrument }\end{array}$ & $\begin{array}{c}\text { Build or } \\
\text { enhance } \\
\text { process } \\
\text { components }\end{array}$ & $\begin{array}{c}\text { Build or } \\
\text { enhance } \\
\text { dissemination } \\
\text { components }\end{array}$ & $\begin{array}{c}\text { Configure } \\
\text { workflows }\end{array}$ & $\begin{array}{c}\text { Test } \\
\text { production } \\
\text { system }\end{array}$ & $\begin{array}{c}\text { Test } \\
\text { statistical } \\
\text { business } \\
\text { process }\end{array}$ & $\begin{array}{c}\text { Finalise } \\
\text { production } \\
\text { systems }\end{array}$ \\
\hline
\end{tabular}

2.4 Collect Phase: in this phase, SCAD collected and gathered all necessary data, using an electronic questionnaire, into a SCAD database to apply further processing. SCAD assured that the people, processes and technology were ready to collect the data, from all establishments by preparing a collection strategy, training the collection staff, ensuring collection resources were available including iPads, agreeing terms with any intermediate collection bodies, configuring collection systems to request and receive the data, while ensuring the security of data to be collected. ZonesCorp in this phase provided SCAD with the required information about the contact details of the establishments and fieldwork management, according to their database of establishments. In addition, ZonesCorp managed the relationship between SCAD and data providers, by recording and responding to comments, queries and complaints. Some basic validation rules have been applied by SCAD and ZonesCorp to ensure the structure and integrity of the information received. SCAD captured the collected data and metadata into a suitable electronic environment for further processing, using clerical staff and optical character recognition tools to extract information from electronic questionnaires. Moreover, process metadata associated with collection to ensure the collection were analysed activities have met requirements.

Figure (4): Collect Phase

\begin{tabular}{|l|c|c|c|}
\hline \multicolumn{4}{|c|}{ Collect } \\
\hline Create frame and select sample & Set up collection & Run collection & Finalise collection \\
\hline
\end{tabular}

2.5 Process Phase: this phase describes the cleaning of data and preparation for analysis. In addition, we checked, cleaned, and transformed the input data into statistical outputs by integrating the data from the establishments according to the design specifications. After that, we classified and coded the input data. The statistical analysis team in SCAD reviewed data to identify potential problems, errors and discrepancies such as outliers or missing values, item non-response and miscoding, a process referred to as input data validation. We made it iteratively, validating data against predefined edit rules. Incorrect values were updated while; missing or unreliable, data were replaced with derived new variables after applying arithmetic formulae based on one or more of the variables that were already present in the dataset. Other statistical techniques including applying different model assumptions, summing data for records sharing certain characteristics, determining measures of average and dispersion, were applied to compile the results in a data file, which was used as the input to the "Analysis" phase. This was considered as an intermediate rather than a final file.

Figure (5): Process Phase

\begin{tabular}{|c|c|c|c|c|c|c|c|}
\hline $\begin{array}{c}\text { Integrate } \\
\text { data }\end{array}$ & $\begin{array}{c}\text { Classify \& } \\
\text { code }\end{array}$ & $\begin{array}{c}\text { Review \& } \\
\text { validate }\end{array}$ & $\begin{array}{c}\text { Edit \& } \\
\text { impute }\end{array}$ & $\begin{array}{c}\text { Derive new } \\
\text { variables \& } \\
\text { units }\end{array}$ & $\begin{array}{c}\text { Calculate } \\
\text { weights }\end{array}$ & $\begin{array}{c}\text { Calculate } \\
\text { aggregates }\end{array}$ & $\begin{array}{c}\text { Finalise } \\
\text { data files }\end{array}$ \\
\hline
\end{tabular}


2.6 Analyse Phase: In this phase, statistical outputs were produced, examined in detail and made ready for dissemination. In consultation with ZonesCorp, we transformed the data into statistical outputs. The quality of the outputs produced were validated in accordance with historical data and with our design expectations. SCAD and ZonesCorp ensured in-depth understanding of the outputs collected, before interpreting and explaining the statistics produced. The statistics were reviewed from all perspectives using different tools, and carrying out indepth statistical analyses. We applied primary and secondary non-disclosure. Measures to protect the confidentiality of data and information. In addition, to finalising the outputs we ensured the statistics and associated information were fit for survey purposes and achieved the required quality level, completed consistency checks, determined the level of release, created supporting information, including interpretation, commentary, technical notes, briefings, measures of uncertainty and any other necessary metadata. The results were discussed and presented at a pre-release meeting with internal experts at SCAD and ZonesCorp who approved the statistical content for release.

Figure (6): Analyse Phase

\begin{tabular}{|l|l|c|c|l|}
\hline Prepare draft outputs & Validate outputs & $\begin{array}{c}\text { Interpret \& } \\
\text { explain outputs }\end{array}$ & $\begin{array}{c}\text { Apply } \\
\text { disclosure } \\
\text { control }\end{array}$ & Finalise outputs \\
\hline
\end{tabular}

2.7 Disseminate Phase: In this phase, SCAD released the statistical products to ZonesCorp. SCAD updated the systems where data are stored, ready for the dissemination purposes. The products were assessed to meet ZonesCorp needs and include interactive graphics and statistical tables. All ZonesCorp queries and requests for this service were recorded, and responded to within agreed deadlines. ZonesCorp requests for micro-data access were recorded, and responses were provided within agreed deadlines. These queries and requests were regularly reviewed by SCAD to provide an input to the over-arching quality management process, as they could indicate new or changing user needs.

Figure (7): Disseminate Phase

\begin{tabular}{|c|c|c|c|c|}
\hline \multicolumn{4}{|c|}{ Disseminate } \\
\hline $\begin{array}{c}\text { Update output } \\
\text { systems }\end{array}$ & $\begin{array}{c}\text { Produce } \\
\text { dissemination } \\
\text { products }\end{array}$ & $\begin{array}{c}\text { Manage release of } \\
\text { dissemination } \\
\text { products }\end{array}$ & $\begin{array}{c}\text { Promote } \\
\text { dissemination } \\
\text { products }\end{array}$ & $\begin{array}{c}\text { Manage user } \\
\text { support }\end{array}$ \\
\hline
\end{tabular}

2.8 Evaluate Phase: SCAD and ZonesCorp evaluated the project by, drawing on a range of quantitative and qualitative inputs, and identified and prioritised potential improvements. We gathered all inputs, and made them available for the team producing the evaluation. We analysed the evaluation inputs and prepared an evaluation report. The resulting report noted all quality issues specific to this project about the statistical business process, and made recommendations for future improvements. An action plan was developed based on the evaluation report. Many meetings were held between SCAD and ZonesCorp including consideration of a mechanism for monitoring the impact of those actions, which provide an input to evaluations of future iterations of the process.

Figure (8): Evaluate Phase

\begin{tabular}{|l|l|l|}
\hline \multicolumn{3}{|c|}{ Evaluate } \\
\hline Gather evaluation inputs & Conduct evaluation & Agree an action plan \\
\hline
\end{tabular}

\section{Result}

In line with the priorities of statistical work and with the urgent needs to devolve statistical indicators in support of the Abu Dhabi Plan, SCAD completed this project successfully by cooperating with key stakeholders in the development and diversification of the Abu Dhabi economy.

SCAD carried out a field survey in 2018 in cooperation with the Higher Corporation for Specialized Economic Zones for the establishments operating under ZonesCorp. The project included designing the survey instrument, which included the following variables: establishment's information, financial statements for 2017, research and development data and logistics information (top 5 countries for exports \& imports, Road transport, Sea transport, Sea Port of choice, Air transport, Airport of choice, Location and storage space) related to the establishments. SCAD built an electronic link for the survey instrument, prepared scientific material for the survey, selected, recruited and training enumerators (Field Researchers) and data editors, revised and coded the data, classified by the International Standard Industrial Classification of All Economic Activities, based on Revision 4 (ISIC,Rev.4), extracted and analysed the results. The survey comprised all active establishments in ZonesCorp during the reference year 2017. All stages of the project was completed within approximately one and a half years. The main outputs results were; the number of employees, compensation of employees, main and secondary revenue, intermediate consumption, value added, gross fixed capital formation, depreciation, research and development 
variables and logistic information.

\section{Discussion and Conclusion:}

This is the first time SCAD conducted this project togother ZonesCorp with, and consider it as a base year survey. The most important objectives of this survey was to estimate the contribution of establishments operating inside ZonesCorp to the GDP of Abu Dhabi Emirate. Research and development is also an important indicator of economic development in the Emirate of Abu Dhabi and it was included as one of the main variables in this survey. The third important objective focused on logistics information for the facilities of ZonesCorp and its proximity to air and marine airports and land ports for the ease and cost of transporting raw materials and finished goods to and from the Emirate.

The official statistics produced by this project will help decision-makers while making important decisions during the future planning process for establishing investment initiatives at the Emirate level. The study will also be a reference source for the United Arab Emirates Government when making relevant decisions in building industrial investment cities.

\section{References}

http://www.zonescorp.com/ar/about-us/corporate-social-responsibility-csr

https://www.scad.gov.abudhabi/ar/pages/default.aspx

https://statswiki.unece.org/display/GSBPM/GSBPM+v5.0

United Nations, (2008), International Standard Industrial Classification of All Economic Activities, Rev.

\section{Appendix:}

\subsection{Charts of steps of preparing the specialized survey project}

\section{Chart (1): Specify Needs Phase}

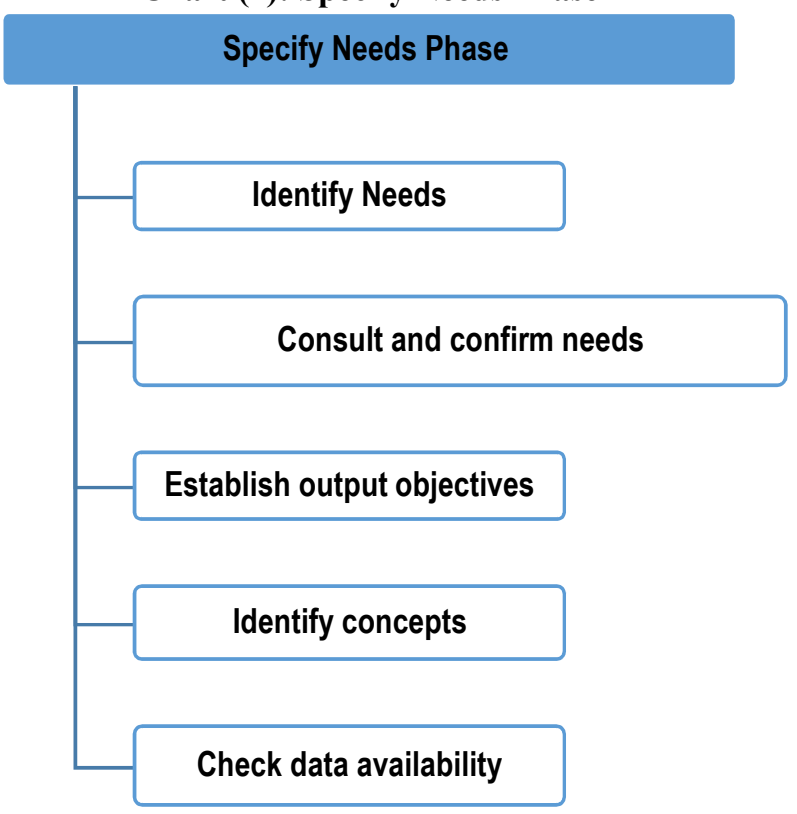

Chart (2): Design Phase

\section{Design Phase}

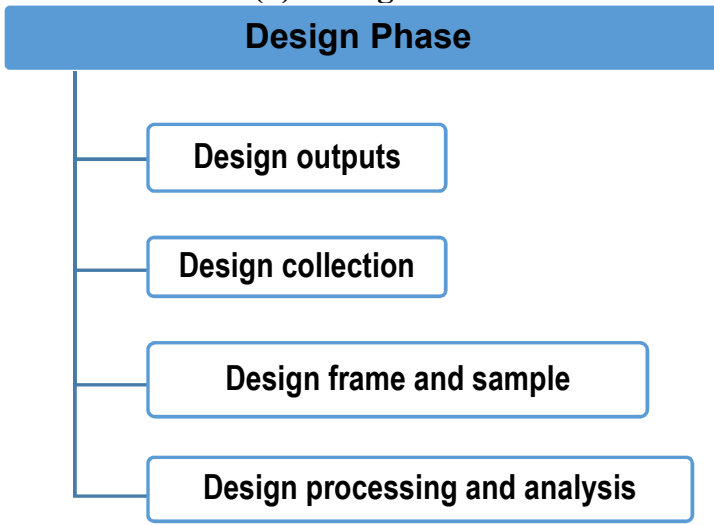


Chart (3): Build Phase

\section{Build Phase}

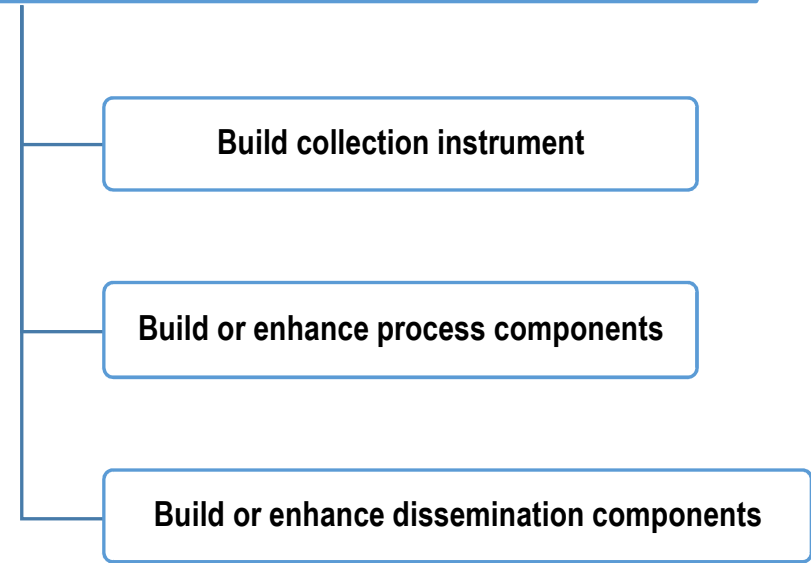

Chart (4): Collect Phase

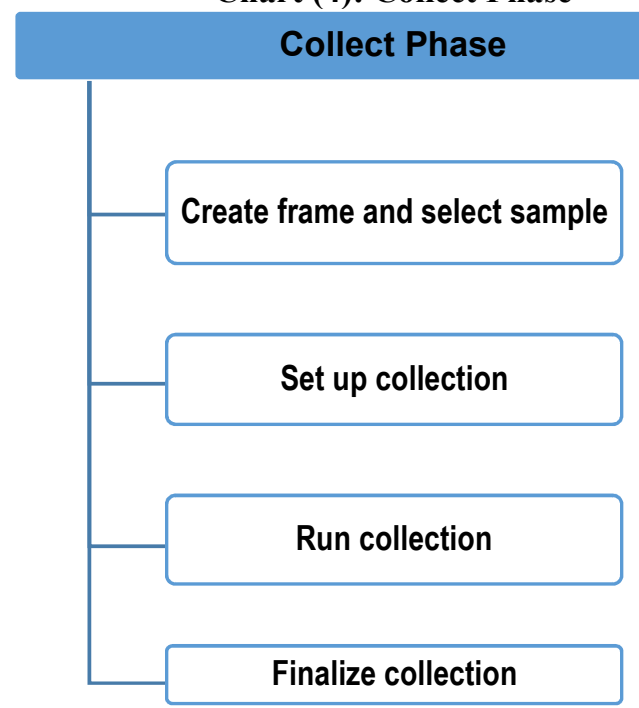

Chart (5): Process Phase

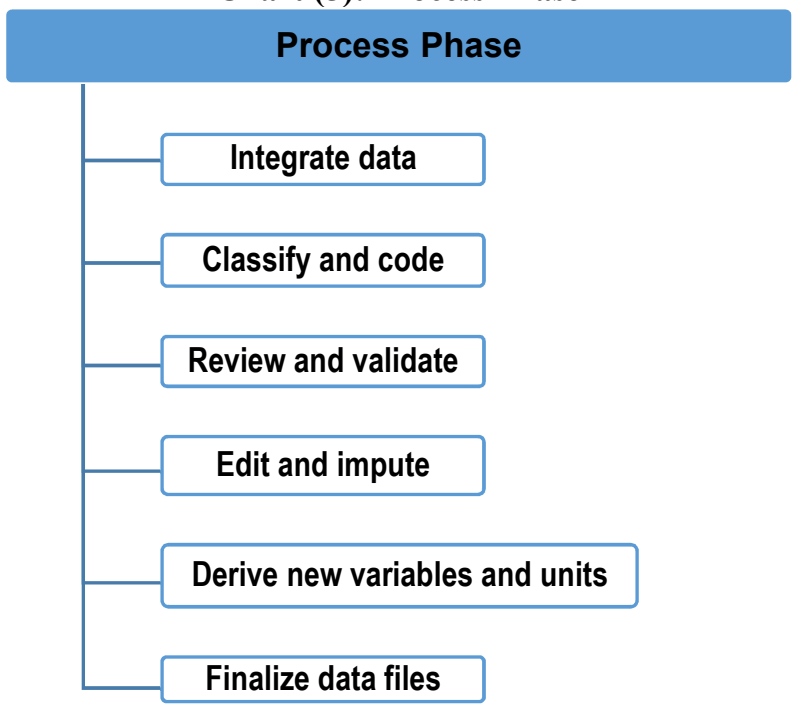


Chart (6): Analyze Phase

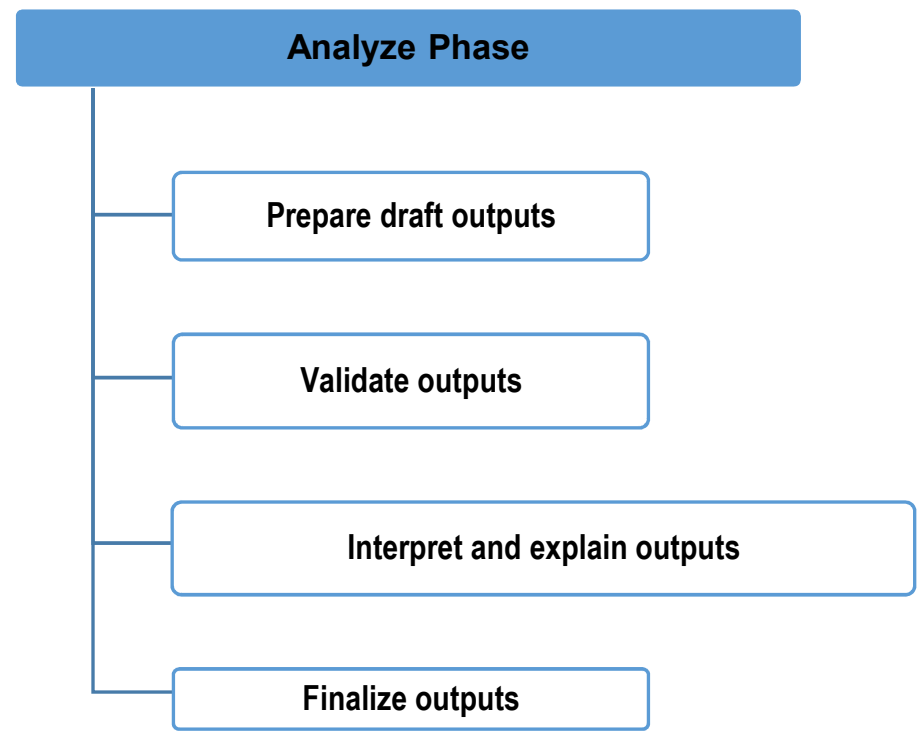

Chart (7): Disseminate Phase

Disseminate Phase

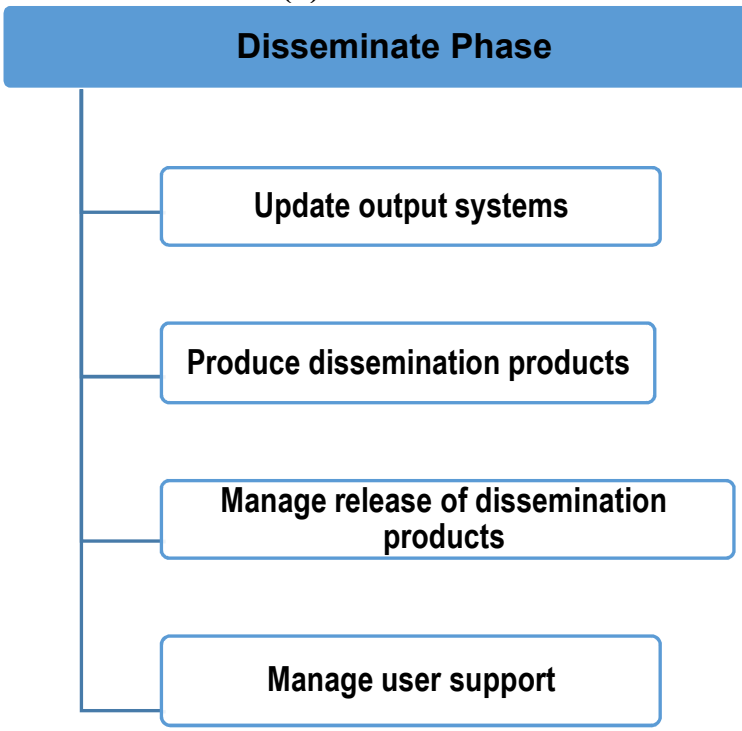

Chart (8): Disseminate Phase

Evaluate Phase

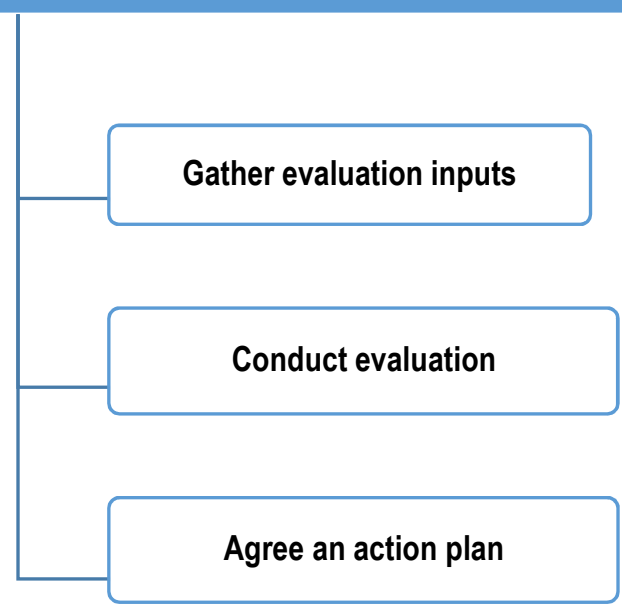




\subsection{Tables:}

Table (1): Economic Output indicators

\begin{tabular}{|c|c|c|c|c|c|c|c|c|c|c|}
\hline ISIC4_4DIG & $\begin{array}{l}\text { Description } \\
\text { of the main } \\
\text { economic } \\
\text { activity }\end{array}$ & $\begin{array}{c}\text { Number } \\
\text { of } \\
\text { employees }\end{array}$ & $\begin{array}{l}\text { Compensation } \\
\text { of employees }\end{array}$ & $\begin{array}{c}\text { Secondary } \\
\text { income }\end{array}$ & $\begin{array}{l}\text { Main } \\
\text { income }\end{array}$ & $\begin{array}{l}\text { Total } \\
\text { revenue }\end{array}$ & $\begin{array}{c}\text { Raw } \\
\text { materials } \\
\text { used in } \\
\text { production }\end{array}$ & $\begin{array}{l}\text { Intermediate } \\
\text { consumption }\end{array}$ & $\begin{array}{l}\text { Value } \\
\text { Added }\end{array}$ & $\begin{array}{l}\text { Capital } \\
\text { formation }\end{array}$ \\
\hline
\end{tabular}

Table (2): Logistic Output indicators

\begin{tabular}{|c|c|c|c|c|c|c|c|c|c|c|}
\hline ISIC4_4DIG & $\begin{array}{l}\text { Description } \\
\text { of the main } \\
\text { economic } \\
\text { activity }\end{array}$ & $\begin{array}{l}\text { Capital } \\
\text { products }\end{array}$ & $\begin{array}{c}\text { Waste and } \\
\text { Scraps } \\
\text { of } \\
\text { Production }\end{array}$ & $\begin{array}{l}\text { Semi-Finished } \\
\text { Production }\end{array}$ & $\begin{array}{c}\text { Other } \\
\text { finished } \\
\text { products }\end{array}$ & $\begin{array}{c}\text { Finished } \\
\text { Production }\end{array}$ & $\begin{array}{c}\text { Customers } \\
\text { and } \\
\text { suppliers }\end{array}$ & $\begin{array}{c}\text { Ports } \\
\text { and } \\
\text { airports }\end{array}$ & $\begin{array}{c}\text { raw } \\
\text { materials }\end{array}$ & $\begin{array}{c}\text { Means of } \\
\text { transportation }\end{array}$ \\
\hline
\end{tabular}

Table (2): Research \& Development Output indicators

\begin{tabular}{|c|c|c|c|c|c|}
\hline ISIC4_4DIG & $\begin{array}{c}\text { Description } \\
\text { of the main } \\
\text { economic } \\
\text { activity }\end{array}$ & $\begin{array}{c}\text { The budget for } \\
\text { research and } \\
\text { development }\end{array}$ & $\begin{array}{c}\text { Total expenditure on } \\
\text { 'internal' }\end{array}$ & $\begin{array}{c}\text { Number of } \\
\text { employees } \\
\text { working on } \\
\text { 'internal' }\end{array}$ & $\begin{array}{c}\text { Total expenditure on the funding of } \\
\text { research and development by the } \\
\text { establishment that is performed by } \\
\text { other organizations }\end{array}$ \\
\hline
\end{tabular}

